\title{
Research on Inter-continent Transmission Efficiency under Northern-hemisphere Energy Connection Mode
}

\author{
Xiaoxia Wei ${ }^{1, a}$ \\ ${ }^{1}$ Department of Energy Strategy and Planning Research, State Grid Energy Research Institute, \\ 100053, China \\ a20583853@qq.com
}

\section{Keywords: Wind; Solar; Transmission efficiency; Connection Mode}

\begin{abstract}
Relying on the northern-hemisphere energy connection, considering the energy implementation, carrying out clean energy alternative is mainly to use the clean energy to take place of fossil energy. Under the green development scenario, this research gives the northern-hemisphere energy interconnection development model, makes the Artic as the connection points, gives the Northern hemisphere interconnection model unite the whole world energy. This research also identifies the factors effecting the transmission changes cost, including generation cost, transmission cost and landing cost. And take Asia and Europe continents connection as the prediction example, estimate these two continents cost benefit and variable power-jointed scheme cost competitiveness. It showed that the trans-continent mode had better benefit, and the landing cost is good to be used, can solve the pollution and energy restriction.
\end{abstract}

\section{Introduction}

Energy is an important affection to the development of human civilization [1]. The development of world energy has experienced changes from high carbon to low carbon, from low efficiency to high efficiency, from partial equilibrium to large scale configuration [2].

Global energy supply is constrained by resource reserves and rising supply costs. To the amount, fossil energy reserves are limited, non-renewable, large-scale development and utilization will lead to depletion of resources. To the layout, the world's energy resources and consumption are reverse distribution; energy exploitation is centralizing to a few countries and regions [3] [4].

The supply costs of fossil and clean energy is showing a "one rising and one dropping". With the coal, oil, natural gas wide exploration, the marginal cost of fossil energy will gradually development of the degree of continuous improvement of the future development of will gradually increase, and will increasing the energy cost, while the clean energy cost is gradually declining, but now it is at a high level. With the rapid development of clean energy technology, the cost will decrease.

So we really need to exploit the rich energy areas, and transport the energy to the developed areas short of energy. Connect the northern hemisphere continents together and balance the supply and demand, can make Asia and Europe has good energy usage system [5] [6][7].

\section{Northern Hemisphere Interconnection Mode}

Northern Hemisphere Interconnection model is mainly based on the Arctic power transmission channel. On one hand, it is carrying the Greenland, Norway, Barents Sea, Kara Hai, Bering Strait, while on the other hand, it is a global energy Internet strategy platform connecting Arctic wind power base for electricity delivery needs, on the other hand, it can realize northern hemisphere three continents connection, forming the global energy interconnection strategy platform.

Northern Hemisphere interconnection model not only can solve the problem of wind power transmission in the Arctic region, but also can satisfy supply and demand gap in Northeast Asia, Europe and North America, taking the Bering Strait, Greenland, Norwegian Sea and Barents Sea as the fulcrums in realizing the Arctic region, Europe and North America connection. This 
connection can give full play to great grid connection; give many benefits of peak and valley regulation, mutual backup, cross-complementarity. In addition, making use of the time difference between the continents, send the Arctic wind power to other continents, meet the day peak load needs, and improve Arctic wind power utilization efficiency.

Table 1. Global Energy Interconnection Development Model

\begin{tabular}{|c|c|c|c|}
\hline Connection & Sending and receiving & Line setting & $\begin{array}{l}2050 \text { transmission } \\
\text { capacity }\end{array}$ \\
\hline $\begin{array}{l}\text { Arctic to } \\
\text { Northeast } \\
\text { Asia }\end{array}$ & $\begin{array}{l}\text { 1、The Kara Sea wind power base of } \\
\text { The Arctic to North China, } \\
\text { 2、 Bering Strait wind power base to } \\
\text { North China, Japan and South } \\
\text { Korea. }\end{array}$ & $\begin{array}{l}\text { 1、 Adopt overhead lines } \pm 1100 \mathrm{kV} \\
\text { HVDC transmission technology to } \\
\text { China's power transmission channels, } \\
\text { 2、Adopt UHV DC submarine cable to } \\
\text { Japan, South Korea. }\end{array}$ & $\begin{array}{l}\text { Transmission capacity } \\
\text { is } 1.2 \text { trillion } \\
\text { kilowatt-hour / year; } \\
\text { channel capacity is } 240 \\
\text { million kilowatts. }\end{array}$ \\
\hline $\begin{array}{l}\text { Arctic to } \\
\text { Europe }\end{array}$ & $\begin{array}{l}\text { 1. Greenland wind power to the } \\
\text { north of England, } \\
\text { 2、 Offshore wind power in the } \\
\text { Norwegian Sea and the Barents Sea } \\
\text { can be sent to Europe via the land } \\
\text { channel. }\end{array}$ & $\begin{array}{l}\text { Adopt UHV DC submarine cable } \\
\text { connecting Green land South wind } \\
\text { power base to Iceland, then leading to } \\
\text { the north of England. }\end{array}$ & $\begin{array}{l}\text { Transmission } \\
\text { is capacity } \\
\text { kilowatt-hours / trillion } \\
\text { channel capacity is } 160 \\
\text { million kilowatts. }\end{array}$ \\
\hline $\begin{array}{l}\text { Arctic to } \\
\text { North } \\
\text { America }\end{array}$ & $\begin{array}{l}\text { 1、 Bering Strait wind power base to } \\
\text { the western United States load } \\
\text { center } \\
\text { 2、 Southern Greenland wind to the } \\
\text { east coast of Canada, then the } \\
\text { eastern United States to the central } \\
\text { load Ottawa. }\end{array}$ & $\begin{array}{l}\text { Adopt } \pm 1100 \mathrm{kV} \text { HVDC transmission } \\
\text { technology from Quebec to New York }\end{array}$ & $\begin{array}{l}\text { Transmission capacity } \\
\text { is } 1 \text { trillion } \\
\text { kilowatt-hours / year; } \\
\text { channel capacity is } 200 \\
\text { million kilowatts. }\end{array}$ \\
\hline
\end{tabular}

\section{Wind Power, Solar and Other Renewable Energy Transmission Efficiency Model}

Northern-hemisphere Energy Connection Construction has transmission economy. On one hand, send low cost power from large-scale renewable energy sources to high generation cost power receiving area, which can reduce the power supply cost of receiving area. On the other hand, with the reduction of the internal and external costs of various types of power generation technologies, the power generation cost is nearly to the fossil power generation, but considering the constraint of future fossil energy resources, the renewable energy costs will increase gradually.

Transmission efficiency is mainly to compare the landing cost with generation cost of sending area, analyse its economic efficiency. Considering the development mode of the global energy interconnection, the research on transmission benefit identification is divided into four levels. The identification and analysis process is:

(1) Research on the generation cost, considering the quantity of resource, renewable base construction and transmission cost, the trend of the internal and external costs of various types of power generation technologies in the future, given sending power base with multiple energy compound mode generation cost.

(2) research on the transmission cost, considering the changing trend of network transmission and technology cost of all continents, combing with transmission line cost fluctuation trend, and line loss, given the sending and receiving areas transmission costs.

(3) Research on the landing cost, considering all continents and different countries tariff with discrepancy calculation, calculate the receiving area landing cost of different power combination programs.

(4) Research on the transmission efficiency, comparing the basic and connection program, the sending efficiency global connection and without connection. 


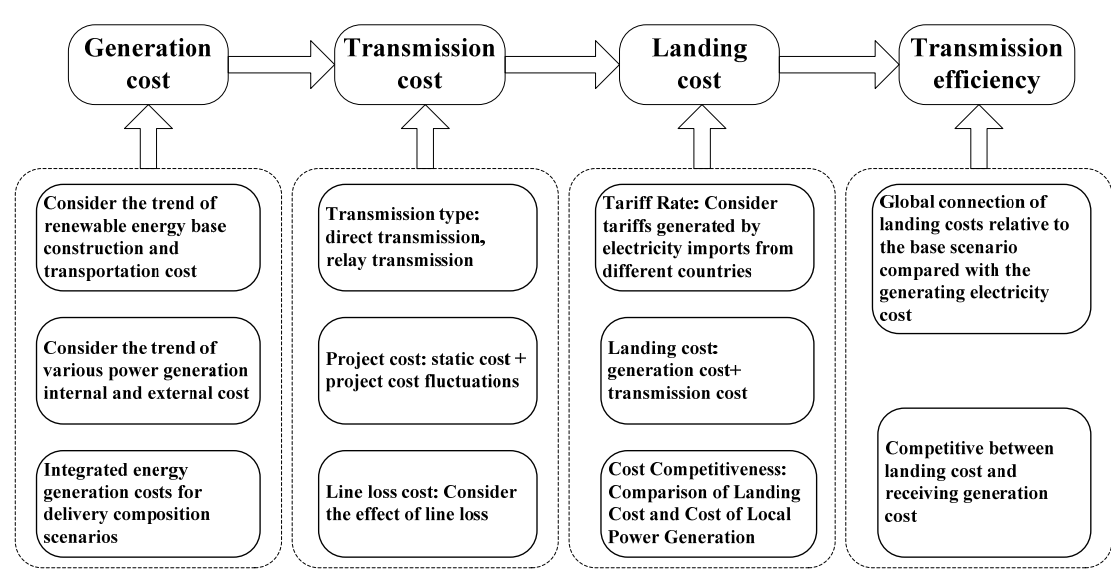

Fig. 1.Analysis process of transmission efficiency

\section{The generation cost of renewable energy}

The sending area's generation cost, is considering renewable energy generation cost and different energy delivery compound mode.

(1) Considering the characteristics of resources in each region, identify the trend of the renewable energy base construction and transportation cost.

(2) Considering the development trend of power generation technology, identify the trend of various power generation internal and external costs

(3) Identify the costs of different electricity generation, such as hydropower, gas and coal, according to unit cost, coal price, gas price, utilization hours, tax rate, operating period, power consumption rate, annual operation and maintenance cost, and hydropower station submerged compensation.

(4) Identify the synthetic generation cost under different power combing scheme, considering the proportion capacity of wind power and solar energy, hydropower regulatory capacity of the flood season, the regulation of gas and electricity capacity.

Wind and solar power, with the variable characteristic renewable energy, bring new challenge to the power system. For the restriction of these two generation technique suffering from wind and solar resource, they can not maintain better power supply balance. In the future, system and market will be united, and become the founder of renewable energy large-scale implementation. Focus on three fields: (1) improve the net benefit of wind and solar power generation at maximum and using this benefit into the whole system. (2) improve the management strategy, adopting the advancer renewable energy prediction method and enhancing power plant distribution method. (3) Increase the extra auxiliary work, adding demanding resource, storage, grid foundation equipment and flexible equipment usage.

In 2015, wind and solar power generation amount accounts $90 \%$ to the total new power increased. Between 2008 and 2015, the land wind power's average cost decreased about 35\%. While the solar power generation cost decreased about $80 \%$. More and more evidence showed that, the nest generation wind and solar power generation technique will be more mature, and much more economy, which can push the wind and solar into the widely usage.

Costs refer to global average of levelised cost of electricity (LCOE) with country specify assumptions on investment costs and cost of financing. Different costs per country are averaged weighted by annual capacity additions. 


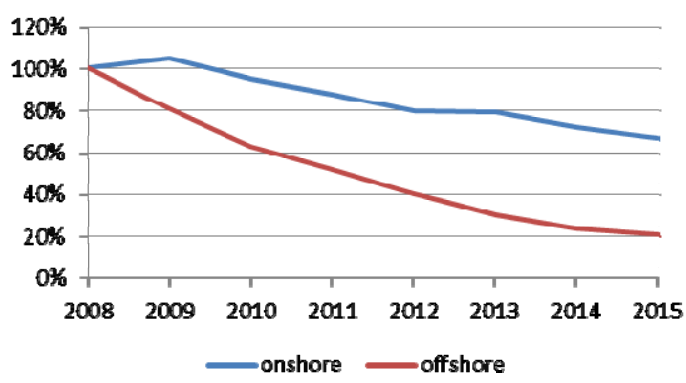

Fig. 2. 2008-2015 wind and solar power generation cost curve

Under the energy Interconnection model, considering the renewable energy resource constraints, the incentive to reduce the cost of power generation, the sending port will use more renewable energy, the price of electricity is much more competitive. The sending port's renewable energy bases, established in the area of wind and solar energy, facing the energy bundling sending out, its cost will decrease gradually. The solar energy LCOE will decrease from $0.13 \mathrm{dollar} / \mathrm{kw} \cdot \mathrm{h}$ of 2015 , to $0.055 \mathrm{dollar} / \mathrm{kw} \cdot \mathrm{h}$ of 2025 , the decreasing ratio is $59 \%$. The onshore wind cost will drop to $0.053 \mathrm{dollar} / \mathrm{kw} \cdot \mathrm{h}$ of 2025 , affected by wind tower, generator, wind farm development and other factors. Consider the renewable energy cost trend, the energy persistence, fast impact the coal, gas and other fossil energy. In the future, the solar and wind power sending costs will have more advantage.

\section{Transmission cost of transmission channel}

Transmission costs of transmission channels, depends on how to select transnational power transmission mode, the corresponding project cost and the cost of fluctuations in different countries, line loss and the cost of electricity in different countries and settlement changes in the situation and other issues.

(1) The choice of power transmission type, consider power supply and demand of inter-continent and inter-country, analyse the advantage of choosing direct or continuous transmission mode, analysis characteristics of UHV DC transmission project, transmission channel characteristics, utilization hours and its supporting power supply, including the grid to provide the price of transmission services

(2) Engineering cost, combined with the above project planning to estimate the static cost of construction, project cost fluctuations, the relevant technical costs of the project cost-related.

(3) The line losses cost, should be calculated on the basis of the principle of tariff balance. It is assumed that the cost of landing is the settlement price of the grid companies that provide transmission services and the grid companies in the receiving areas, which is equivalent to the cost of local power purchase.

$$
\begin{aligned}
& C_{\text {lineloss }}=C_{\text {generation }} \times K /(1-K) \\
& C_{\text {lineloss }} \text { is line loss cost, } C_{\text {generation }} \text { is generation cost, } K \text { is line loss. }
\end{aligned}
$$

\section{The receiving area landing cost}

The receiving area landing cost refers to the receiving area getting the sending renewable energy adds the transmission cost.

$$
C_{\text {landing }}=C_{\text {generation }}+C_{\text {line }}\left(C_{\text {lineloss }}\right)+T_{\text {tariff }}
$$

$C_{\text {landing }}$ is landing cost, $C_{\text {line }}$ is transmission cost, $T_{\text {tariff }}$ is tariff.

(1) Landing Cost should be calculated according to the cumulative principle of cost. Power transmission projects across continents, need to consider cross-border tariffs generated by different countries when electricity imports. Each transit country should be a link, based on DC lines, converter stations and supporting exchange projects in the country's investment were calculated transmission costs and line loss costs, the country's landing costs and based on the country's tariff 
rate The resulting tariffs are added together as the cost of the next country's electricity generation.

(2) There are relay points in some countries. In the landing cost calculation, the DC cost of the before relay point and the cost of electricity generated by the surplus electricity are taken as the DC generation cost, which can be used as after the power-weighted average of the respective country.

\section{The landing cost competitiveness}

The landing cost competitiveness is to analysis and comparison, under the basic and global interconnection scenarios, the use of different energy combinations in the form of energy transmission area, compared with the cost of receiving electricity in the renewable energy power generation. The lower the landing cost, the more competitive the corresponding price will be, and it will have the better economical, the transmission efficiency will be obviously.

$$
P=\left(1-C_{\text {landing }} / C_{\text {generation }}\right) * 100 \%
$$

$P$ is the landing cost competitiveness.

\section{Prediction}

Taking the most feasible connection of Asia and Europe as an example, make up six intercontinental transmission schemes on two continents, which are estimated according to the investment of DC transmission project.

\section{(1)The prediction of power generation cost}

Consider the proportion of wind and solar capacity, hydropower flood season adjustment, gas power adjustment; it can get different power generation cost.

Table 2. The cost analysis of sending side power-jointed

\begin{tabular}{|c|l|c|c|}
\hline & \multicolumn{1}{|c|}{ program design } & synthesized generation cost (yuan/kWh) & Synthesized hour(h) \\
\hline 1 & $\begin{array}{l}\text { Kazakhstan gas / hydro + China } \\
\text { Xinjiang wind power }\end{array}$ & 0.4601 & 6000 \\
\hline 2 & $\begin{array}{l}\text { Kazakhstan gas / hydro + China } \\
\text { Xinjiang + Mongolia solar wind } \\
\text { power }\end{array}$ & 0.4978 & 5800 \\
\hline 3 & $\begin{array}{l}\text { China Xinjiang wind power }+ \\
\text { Russia Siberia hydropower }\end{array}$ & 0.4962 & 5900 \\
\hline
\end{tabular}

(2)Tariff

China's tariff rate ranges from $0 \%$ to $35 \%$, Poland ranges from $0 \%$ to $15 \%$ (average $4.2 \%$ ), and Germany ranges from 5\% to 17\%.By the end of 2011, Russia, Belarus, Kazakhstan, the three countries jointly created the Eurasian Economic Commission, on September 1 of 2014 , the weighted average tariff rate fell to $7.1 \%$.In this research, it chooses the rate can be seen by this table.

Table 3. Tariffs along the lines

\begin{tabular}{|c|c|}
\hline country & Calculation tariff $(\%)$ \\
\hline China & 17 \\
\hline Kazakhstan & 7.1 \\
\hline Russia & 7.1 \\
\hline Belarus & 7.1 \\
\hline Poland & 4.2 \\
\hline Germany & 11 \\
\hline
\end{tabular}

(3)The loss rate prediction

$\pm 800, \pm 1100$ kilovolt converter station power loss is generally between $0.5 \%$ to $1 \%$, this research make the value as $0.75 \%$.

\section{(4)The transmission cost prediction}

According to the transmission scheme and power-jointed program mentioned above, and combine with basic usage hour, can get the relative transmission cost. 
Table 4. The corresponding transmission $\operatorname{cost}(\mathrm{yuan} / \mathrm{kWh})$

\begin{tabular}{|c|c|c|c|c|c|c|}
\hline & one $/ 1$ & one $/ 2$ & two/1 & two/2 & three/1 & three/2 \\
\hline Transmission cost 1 & 0.126225 & 0.140363 & 0.135270 & 0.149710 & 0.185018 & 0.201080 \\
\hline Transmission cost 2 & 0.078844 & 0.081095 & 0.078844 & 0.081095 & $/$ & $/$ \\
\hline
\end{tabular}

(5)The landing cost

According to the relative basic usage hour and its calculation method, can get each transmission scheme landing cost and cost competitiveness.

Table 5. the relative landing cost and competitiveness analysis(yuan $/ \mathrm{kWh} 、 \%$ )

\begin{tabular}{|c|c|c|c|c|c|c|}
\hline & one/1 & one/2 & two/1 & two/2 & three/1 & three/2 \\
\hline Landing cost & 0.9905 & 1.0566 & 0.9121 & 0.9699 & 1.0768 & 1.1694 \\
\hline cost competitiveness & 17.46 & 11.95 & 24.00 & 19.17 & 10.27 & 2.55 \\
\hline
\end{tabular}

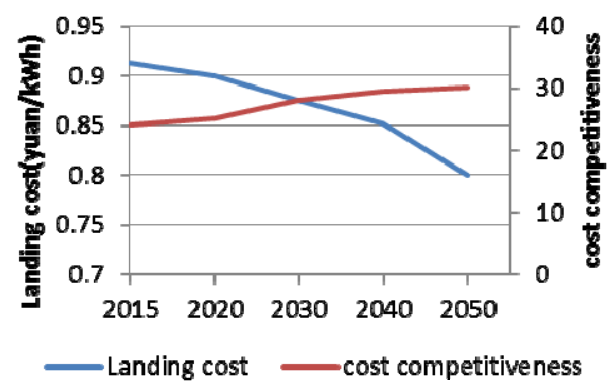

Fig. 3. Under scheme two/1 analyse the landing cost and cost competitiveness

In the scheme above, the landing cost of two/1 is lowest, and cost competitiveness is highest. While the landing cost of three/ 2 is highest, and cost competitiveness is the lowest. This showed that the relative landing cost of scheme two is higher than the scheme one. The relay transmission program's landing cost is lower than the direct transmission program. The power scheme two is higher than scheme two and three. So scheme two's line loss cost is lower than other two schemes.

While the scheme one and three covers one more country than scheme two. And because of China is the DC original point, considering the tariff of covering countries, offset the making Kazakhstan as the original point scheme's transmission loss affection. So the landing cost of scheme one and three is higher than two. And the tariff of scheme three is obvious high. Cost competitiveness of direct scheme can not get the same affection with relay scheme. The landing cost of scheme one and two is lower than scheme three.

Fig. 3 gives the 2015-2050 landing cost and cost competitiveness. Considering all kinds of factors, as the jointed power basement reset power proportion of the scheme one and two is the same, the after generation power cost of scheme one is higher than scheme two. We can get the result is that; the lower of generation cost, the landing cost affected by generation cost will be great.

\section{Conclusion}

The global clean energy resources are rich, water resources are more than 10 billion kilowatts, wind energy resources exceeds 1 trillion kilowatt, and solar energy resources exceed 100 trillion kilowatts, surpassing the human society. This research gives the northern-hemisphere energy interconnection development model, through the northern hemisphere interconnection model and equator interconnection model can unite the whole world energy. It also identifies the factors effecting the transmission changes cost, including generation cost, transmission cost (line loss) and landing cost. And take Asia and Europe connection as the prediction example, estimate these two continents cost benefit and variable power-jointed scheme cost competitiveness. The research showed that under the global energy interconnection mode, the trans-continent mode had better benefit, and the landing cost is good to be used, can solve the pollution and energy restriction. 


\section{References}

[1] TIAN Xin, SUN Yanlong, NIU Xinsheng, ZHU Xiubo, ZHAO Guangfeng. Power Transmission Mode to Promote Low-Carbon Development of Load Center [J]. Power System Technology. 2015(39) 663-668.

[2] WEI Xiaoxia, ZHANG Jinfang, HUANG Han. Research on Russian Far East Siberia Power Supply System Based on Global Energy Internet Patterns[J]. Electric Power. 20163(46) 46-50.

[3] WEI X, ZHANG Ji, HUANG H. Research on Russian Far East Siberia Power Supply System Based on Global Energy Internet Patterns [J]. Power System Technology.2015( 39) 46-50.

[4] YANG Hao, WANG Dan, LIU Dichen. Establishment of UHV AC transmission model and economical optimization strategy [J]. Power System Protection and Control. 2015(43)91-96.

[5] Huang Yi, Wang Zhidong, Liu Jianqin. Zhang Lin, Li Jun. Economic analysis of wind power by UHV DC Transmission [J]. Electric Power Construction. 20115(32)100-103.

[6] Xu Jun. Benefit and efficiency analysing models on china's power exchange among regions [C]. North china electric power university.2013.

[7] Sun Bo. Transmission system planning and operation mode considering renewable energy power generation [C]. Zhejiang University. 2015. 